\title{
A NOTE ON THE COMPLETE CONSISTENCY FOR THE WEIGHTED LINEAR ESTIMATOR OF NONPARAMETRIC REGRESSION MODELS
}

\author{
Hui Wang, Yuting Fang, Ling Chen, Mengmei Xi And Xuejun Wang*
}

\begin{abstract}
In this paper, we study the complete consistency for the estimator of nonparametric regression models based on extended negatively dependent random errors by using the exponential inequalities and the truncation method. In particular, if $E|X|^{1+p}<\infty$ for some $p>1$, then the result also holds, which improves the corresponding one in the literature. As an application, the complete consistency for the nearest neighbor estimator is obtained. Finally, the simulation study is provided to verify the validity of the theoretical result.
\end{abstract}

Mathematics subject classification (2020): 62G20.

Keywords and phrases: Nonparametric regression model, complete consistency, END random variables, nearest neighbor estimator.

\section{REFERENCES}

[1] Y. Chen, A. Chen, K. W. NG, The strong law of large numbers for extend negatively dependent random variables, Journal of Applied Probability, 47, 908-922, 2010.

[2] Z. CHEN, C. LU, Y. SHEN, R. WANG, X. J. WANG, On the complete and complete moment convergence for weighted sums of ANA random variables and applications, Journal of Statistical Computation and Simulation, 89 (15), 2871-2898, 2019.

[3] Y. FAN, Consistent nonparametric multiple regression for dependent heterogeneous processes, Journal of Multivariate Analysis, 33(1), 2-88, 1990.

[4] A. A. GEORGIEv, Local properties of function fitting estimates with applications to system identification, In: Grossmann W., Pflug G., Vincze I., Wertz W. (Eds.), Mathematical Statistics and Applications, Volume B, Proceedings of the 4th Pannonian Symposium on Mathematical Statistics, 4-10, September, 1983, Bad Tatzmannsdorf, Austria, Reidel, Dordrecht, 141-151, 1985.

[5] A. A. GeORGIEV, W. GREBLICKI, Nonparametric function recovering from noisy observations, Journal of Statistical Planning and Inference, 13 (1), 1-14, 1986.

[6] A. A. Georgiev, W. GReblicki, Consistent nonparametric multiple regression, Journal of Multivariate Analysis, 25 (1), 100-110, 1988.

[7] T.-C. HU, K. L. WANG, A. Rosalsky, Complete convergence theorems for extended negatively dependent random variables, Sankhyā A: The Indian Journal of Statistics, 77 (1), 1-29, 2015.

[8] K. JoAg-Dev, H. RobBIns, Negative association of random variables with applications, The Annals of Statistics, 11 (1), 285-295, 1983.

[9] H. Y. LIANG, B. Y. JING, Asymptotic properties for estimates of nonparametric regression models based on negatively associated sequences, Journal of Multivariate Analysis, 95, 227-245, 2005.

[10] E.L. Lehmann, Some concepts of dependence, The Annals of Mathematics Statistics, 37, 1137$1153,1966$.

[11] L. LiU, Precise large deviations for dependent random variables with heavy tails, Statistics and Probability Letters, 79, 1290-1298, 2009.

[12] H. G. MÜLLER, Weak and universal consistency of moving weighted averages, Periodica Mathematica Hungarica, 18 (3), 241-250, 1987.

[13] D. H. Qiu, P. Y. Chen, R. G. Antonini, A. Volodin, On the complete convergence for arrays of rowwise extended negatively dependent random variables, Journal of the Korean Mathematical Society, 50 (2), 379-392, 2013. 
[14] G. G. Rouss As, Consistent regression estimation with fixed design points under dependence conditions, Statistics and Probability Letters, 8, 41-50, 1989.

[15] G. G. Rouss As, L. T. TRAn, D. A. IoAnnides, Fixed design regression for time series. asymptotic normality, Journal of Multivariate Analysis, 40, 262-291, 1992.

[16] A. T. SHEN, On the strong convergence rate for weighted sums of arrays of rowwise negatively orthant dependent random variables, RACSAM, 107 (2), 257-271, 2013.

[17] A. T. SHEN, Complete convergence for weighted sums of END random variables and its application to nonparametric regression models, Journal of Nonparametric Statistics, 28, 702-715, 2016.

[18] A. T. Shen, Y. Zhang, A. Volodin, Applications of the Rosenthal-type inequality for negatively superadditive dependent random variables, Metrika, 78, 295-311, 2015.

[19] C. J. Stone, Consistent nonparametric regression, The Annals of Statistics, 5, 595-645, 1977.

[20] L. T. Tran, G. G. Roussas, S. Yakowitz And B. T. VAn, Fixed-design regression for linear time series, The Annals of Statistics, 24, 975-991, 1996.

[21] X. J. WAng, L. L. Zheng, C. XU, S. H. Hu, Complete consistency for the estimator of nonparametric regression models based on extended negatively dependent errors, Statistics-A Journal of Theoretical and Applied Statistics, 49 (2), 396-407, 2015.

[22] Q. Y. Wu, Probability Limit Theory for Mixing Sequences, Science Press of China, Beijing, 2006.

[23] Q. Y. WU, A strong limit theorem for weighted sums of sequences of negatively dependent random variables, Journal of Inequalities and Applications, Volume 2010, Article ID 383805, 8 pages, 2010.

[24] Y. Wu, X. J. WANG, S. H. Hu, Complete moment convergence for weighted sums of weakly dependent random variables and its application in nonparametric regression model, Statistics and Probability Letters, 127, 56-66, 2017.

[25] Y. F. WU, M. GUAN, Convergence properties of the partial sums for sequences of END random variables, Journal of the Korean Mathematical Society, 49, 1097-1110, 2012.

[26] Y. F. Wu, M. C. ORdonEZ, A. Volodin, Complete convergence and complete moment convergence for arrays of rowwise end random variables, Glasnik Matematički, 49 (69), 449-468, 2014.

[27] J. G. YAN, On complete convergence in Marcinkiewicz-Zygmund type SLLN for END random variables and its applications, Communications in Statistics-Theory and Methods, 48 (20), 5074-5098, 2019.

[28] W. Z. YAng, H. Y. XU, L. Chen, S. H. Hu, Complete consistency of estimators for regression models based on extended negatively dependent errors, Statistical Papers, 59 (2), 449-465, 2018. 